\title{
CLINICAL EFFICACY OF A TEA-BAG FORMULATION OF CRYPTOLEPIS SANGUINOLENTA ROOT IN THE TREATMENT OF ACUTE UNCOMPLICATED FALCIPARUM MALARIA
}

\author{
K. A. BUGYEI, G. L. BOYE and M. E. ADDY ${ }^{1}$ \\ Department of Pharmacology, University of Ghana Medical School, College of Health Sciences, University of \\ Ghana, Accra, Ghana and ${ }^{1}$ Department of Biochemistry, University of Ghana, Legon, Ghana \\ Author for correspondence: Dr Kwesi A. Bugyei \\ Conflict of interest: None declared \\ E-mail: kbugyei3@yahoo.com
}

\section{SUMMARY}

Objective: To evaluate the clinical efficacy and safety of a tea bag formulation of the root of $C$. sanguinolenta Design: This is a prospective descriptive open trial.

Setting: Patients were recruited from Korle-Bu, Mamprobi and Dansoman Polyclinics.

Subjects: Forty-four subjects with uncomplicated malaria were recruited for the study.

Method: Patients presented with clinical symptoms of malaria. Laboratory investigations conducted included malaria parasite counts, haematological indices and biochemical tests which were obtained before, during and after a 5 -day treatment period, up to Day 28 posttreatment. All patients in the study were symptomatic with significant parasitaemia. Patients were given one teabag three times a day, that is, morning, noon and night, for five days of treatment.

Results: Fifty percent of the patients were cleared of their P. falciparum parasitaemia by 72 hours, and all by Day 7. Presenting symptoms of fever, chills, nausea and vomiting cleared rapidly, all by Day 3, but resolution of haematological and biochemical abnormalities associated with malaria was generally slow, a feature seen in malaria post-treatment. The overall cure rate was $93.5 \%$ due to two cases of recrudescence on Days 21 and 28. The laboratory findings did not suggest any toxicity.

Conclusion: On the basis of fever clearance and disappearance of parasitaemia by Day 7 , the formulation has been shown to be non-toxic and highly effective in the treatment of acute uncomplicated malaria.

Keywords: Clinical efficacy, Cryptolepis sanguinolenta, falciparum malaria, Ghana, tea bag formulation.

\section{INTRODUCTION}

Cryptolepis sanguinolenta (Landl.) Schlecter syn Pergularia sanguinolenta Lindl., (Asclepiadaceae), which is indigenous to Africa ${ }^{1}$, grows wild as a thinstemmed twining and scrambling shrub along the west coast of Africa. ${ }^{2}$ The root and root bark decoction of
C. sanguinolenta has been used by traditional medical practitioners to treat a number of diseases including malaria. ${ }^{3,4,5,6,7,8,9}$ Although herbal preparations have been used for generations for the treatment of fevers including malaria, there have been very little systematic scientific and clinical studies of most of these preparations. However, a number of scientific studies on preparation of $C$. sanguinolenta have appeared in the literature. Crude extracts of $C$. sanguinolenta and their fractions, as well as indoquinoline alkaloids isolated from the plant, have been shown to have activity against Plasmodium falciparum both in vitro and in vivo. ${ }^{9-13}$ In addition to studies indicating anti-plasmodial effect, extracts of $C$. sanguinolenta have been shown to have anti-microbial activity $^{3,6,14-21}$, to be anti-hyperglycaemic ${ }^{22,23}$ and antiinflammatory. ${ }^{24}$

A preliminary study of the clinical efficacy of an aqueous extract of $C$. sanguinolenta as an anti-malarial preparation had been carried out which indicated the efficacy of the extract against falciparum malaria. ${ }^{25}$ In that study, which was aimed at comparing efficacy of the aqueous extract with chloroquine, the modified WHO extended 7 days in vivo test ${ }^{26}$ was used to measure $P$. falciparum response in a number of malarial patients with parasitaemia of 1,000 to 100,000 $P$. falciparum parasites per 8000 white blood cells. The results of this open, randomized, comparative study indicated that the efficacy of $C$. sanguinolenta in the treatment of falciparum malaria was comparable to that of chloroquine. All the 22 patients in the study responded clinically and asexual parasitaemia was cleared within 7 days. There was no recrudescence of parasitaemia during the follow-up period of 28 days.

There are a number of herbal preparations for the treatment of malaria on the Ghanaian market and most of these are in the form of aqueous decoctions, many of them preserved with chloroform. Chloroform is hepatotoxic and therefore, its use has generally been a matter of concern to many Ghanaian health professionals. 
Thus the formulation of an herbal preparation which avoids the use of preservatives is an advantage. PHYTO-LARIA $^{\circledR}$ is a teabag formulation of $C$. sanguinolenta dried root, with flavouring and without any preservatives. Even though the clinical efficacy of C. sanguinolenta aqueous extract had been established, it was necessary to confirm the clinical efficacy of $C$. sanguinolenta in the new formulation and in the dose prescribed. This study was undertaken to evaluate the clinical efficacy and safety of PHYTO-LARIA ${ }^{\circledR}$ as prescribed in the treatment of symptomatic uncomplicated malaria in semi-immune patients.

\section{METHODS}

\section{Patients}

Patients aged between 11 and 50 years, with clinical features of uncomplicated malaria were recruited into the study. They were screened using thick and thin blood films and those with parasitaemia of between 1000 and 1000,000 P. falciparum per 8000 white blood cells were selected. Patients with complicated malaria, (severe anaemia or cerebral malaria), as well as pregnant and lactating women, were excluded from the study. Patients who had taken therapeutic doses of chloroquine within the previous 14 days, or sulfadoxine/pyremethamine within 28 days were also excluded. Urine screening tests for chloroquine and sulfadoxine/pyremethamine were carried out on all patients before treatment on day 0 and at each followup on days 1, 2, 3, 7, 14, 21 and 28. Subjects who tested positive at any time were excluded from the study. Consent was obtained from all the patients who opted to participate in the study. Parental consent was obtained for young patients and supervision requested in order to improve compliance. The study was cleared by the Ethical and Protocol Review Committee of the University of Ghana Medical School, where the study was based.

\section{Test drug}

The test drug used for treatment in this study was a teabag formulation of $C$. sanguinolenta root powder. Each teabag contained $2.5 \mathrm{~g}$ of the root powder, plus flavourings. The dose given was one teabag three times a day, that is, morning, noon and night, for five days of treatment.

\section{Study plan}

Patients were recruited from three different out-patient clinic sites. This was an out-patient study carried out between the months of September and December 2001. The WHO extended 7-day in vivo test ${ }^{26}$ was used to measure $P$. falciparum response to the formulation.
Patients admitted to the study had their medical history taken and physical examination conducted before treatment started (D0) and on each of the follow-up days (Days 1, 2, 3, 7, 14, 21 and 28). Body temperature, pulse rate, blood pressure and respiratory rate were measured on each visit. The type of malaria was diagnosed by examination of thick and thin blood films and malaria parasite count performed. Parasite counts were repeated during treatment on Days 1, 2 and 3, and subsequently on Days 7, 14, 21 and 28.

In order to assess the efficacy of the formulation the following parameters were measured or derived: parasite clearance time, fever resolution time and recrudescence within the 28 days follow up. The treatment was considered curative if there was clearance of falciparum parasitaemia by Day 7 and no recrudescence during the 28-day follow up period. Fever was defined as axilla temperature above $37.5^{\circ} \mathrm{C}$, and the fever clearance time as the time in hours until the body temperature fell to $37^{\circ} \mathrm{C}$ or less and remained below $37.5^{\circ} \mathrm{C}$ for 24 hours. Improvement in physical signs and symptoms, such as body ache, nausea, dizziness and headache, were also included in the evaluation criteria for efficacy.

The following haematological tests, including haemoglobin $(\mathrm{Hb})$, haematrocrit, reticulocyte count, total white cell count (WBC), platelet count (Automated Haematology Analyzer, Sysmex KX-21, Kobe, Japan) and erythrocyte sedimentation rate (ESR) were done before treatment and on Days 3, 7, 14, 21 and 28 after starting treatment. Biochemical tests carried out using semi-automated clinical chemistry analyzer (Microlab 300, Vital Scientific N.V., The Netherlands) included serum urea and creatinine, bilirubin both total and direct, as well as the enzymes aspartate aminotransferase (ASAT), alanine aminotransferase (ALAT) and alkaline phosphatase (ALP) were measured before, during and after treatment. In addition, serum uric acid, glucose, total proteins and total cholesterol were also measured. Urinalysis for glucose, albumin, blood, urobilinogen, bilirubin and urinary sediment examination were conducted on all the observation days. The clinical and laboratory findings, as well as suspected adverse drug reactions were recorded on standard forms.

\section{Data analysis}

Data was analyzed using SPSS (Version 10.0). Results are presented as mean $( \pm \mathrm{SD})$ or as proportions as appropriate. More than two means were compared using one-way ANOVA with appropriate pairwise post hoc t-tests for isolating groups that were statistically significant. $\mathrm{p}$ values less than 0.05 were considered significant. 


\section{RESULTS}

\section{Patients' characteristics}

Forty-four patients (22 males and 22 females) with acute uncomplicated malaria entered the study. Their mean age was 25.2 (9.2) years and their mean body weight of 60.1 (14.6) $\mathrm{kg}$. By the $7^{\text {th }}$ day, 12 patients had defaulted and one other patient was withdrawn Only one patient in the study had less than $10^{3}$ parasites per $\mu \mathrm{l}$ of blood initially and 2 patients had $10^{5}$ parasites per $\mu 1$ of blood. The rest had between $10^{3}$ and $10^{5}$ parasites per $\mu 1$ of blood (Table 1 ).

More than $50 \%$ of patients were cleared of their $P$. falciparum parasitaemia by $72 \mathrm{~h}$. The mean parasite clearance time was 82.3 (39) h. All the patients evaluated had cleared by Day 7 and, except for two, remained so throughout the rest of the 28 days. There were 2 cases of recrudescence, one occurring on Day 21 and the other on Day 28. The mean initial temperature of the patients in the study was $38.43^{\circ} \mathrm{C}$. The mean fever clearance time was 25.2 (21.2) hours. following the development of upper respiratory infection, diarrhoea and fainting episode. Thirty-one patients, therefore, completed the study. All patients in the study were symptomatic with significant parasitaemia ranging from 924 to 264,857 per $\mu$ of blood (geometric mean $=20892$ ).

Table 2 shows the incidence and duration of presenting symptoms. The commonest presenting symptom was body ache followed by fever, chills, headache, weakness, nausea, vomiting, and abdominal pains. The fever, chills, nausea and vomiting cleared rapidly, all by Day 3, whereas the headaches, body ache, weakness and abdominal pains presented in diminishing number of patients.

Clinical jaundice was noticed in 4 patients before treatment, clearing in all of them by Day 7 posttreatment. Hepatomegaly was observed in 4 patients, resolving in 3 patients by Day 7, and persisting posttreatment in one patient whose condition was severe.

\section{Clinical data}

Table 1 Parasite clearance times of patients in the study according to initial parasitaemia

\begin{tabular}{|c|c|c|c|c|c|c|}
\hline \multirow{2}{*}{$\begin{array}{l}\text { Time } \\
\text { (h) of clear- } \\
\text { ance (up to) }\end{array}$} & \multicolumn{4}{|c|}{ Number of parasites / $\mu$ l of blood } & \multicolumn{2}{|c|}{$\begin{array}{l}\text { Number of patients } \\
\text { cleared (cumulative) }\end{array}$} \\
\hline & $<10^{3}$ & $10^{3}-10^{4}$ & $10^{4}-10^{5}$ & $>10^{5}$ & Total & $\%$ \\
\hline 24 & 0 & 1 & 3 & 0 & 4 & 12.9 \\
\hline 48 & 0 & 1 & 6 & 0 & 11 & 35.4 \\
\hline 72 & 0 & 2 & 4 & 1 & 18 & 58.1 \\
\hline 96 & 0 & 0 & 5 & 0 & 23 & 74.1 \\
\hline 120 & 0 & 1 & 1 & 0 & 25 & 80.6 \\
\hline 144 & 1 & 4 & 0 & 1 & 31 & 100 \\
\hline
\end{tabular}

Table 2 Evolution of presenting symptoms following treatment with PHYTOLARIA ${ }^{\circledR}$. Numbers represent patients expressed as percentage.

\begin{tabular}{|l|l|l|l|l|l|l|l|l|}
\hline \multicolumn{1}{|c|}{ Symptom } & \multicolumn{9}{c|}{ Day } \\
\hline & $\mathbf{0}$ & $\mathbf{1}$ & $\mathbf{2}$ & $\mathbf{3}$ & $\mathbf{7}$ & $\mathbf{1 4}$ & $\mathbf{2 1}$ & $\mathbf{2 8}$ \\
\hline Abdominal Pain & 60.9 & 34.4 & 45.2 & 19.4 & 6.45 & 9.7 & 9.7 & 3.2 \\
\hline Body - ache & 95.6 & 37.5 & 29.0 & 9.7 & 3.2 & 3.2 & 3.2 & 3.2 \\
\hline Chills & 93.3 & 25.0 & 12.9 & 3.2 & 0 & 0 & 0 & 0 \\
\hline Diarrhoea & 13.0 & 6.25 & 6.25 & 9.7 & 3.2 & 6.25 & 3.2 & 3.2 \\
\hline Dizziness & 58.7 & 34.4 & 32.2 & 16.1 & 3.2 & 0 & 0 & 0 \\
\hline Fever & 93.3 & 25.0 & 12.9 & 3.2 & 0 & 0 & 0 & 0 \\
\hline Hallucinations & 17.4 & 9.4 & 3.2 & 0 & 6.25 & 0 & 0 & 0 \\
\hline Headache & 93.3 & 68.7 & 58.1 & 48.4 & 25.8 & 25.8 & 16.1 & 6.25 \\
\hline Nausea & 76.0 & 21.9 & 35.5 & 16.1 & 0 & 0 & 0 & 0 \\
\hline Skin Itch & 2.2 & 3.1 & 6.45 & 0 & 3.2 & 0 & 0 & 0 \\
\hline Vomiting & 58.7 & 9.4 & 32.2 & 9.7 & 0 & 0 & 0 & 0 \\
\hline Weakness & 91.3 & 53.1 & 35.5 & 16.1 & 19.4 & 9.7 & 6.25 & 9.7 \\
\hline
\end{tabular}


Table 3 Patients' haematological parameters for the experimental period. Values are means \pm S.D.

\begin{tabular}{|l|c|c|c|c|c|c|}
\hline \multicolumn{1}{|c|}{ Haematological. } & \multicolumn{5}{c|}{ Day of Experimental Period } \\
\hline \multicolumn{1}{|c|}{ Parameter } & $\mathbf{0}$ & $\mathbf{3}$ & $\mathbf{7}$ & $\mathbf{1 4}$ & $\mathbf{2 1}$ & $\mathbf{2 8}$ \\
\hline Haemoglobin (g/dl) & & & & & & \\
\hline Male [17] & $.7 \pm 1.7$ & $12.1 \pm 1.4$ & $11.7 \pm 1.0$ & $11.8 \pm 0.9$ & $2.0 \pm 1.1$ & $12.5 \pm 1.0$ \\
\hline Female [14] & $11.8 \pm 1.4$ & $10.9 \pm 1.6$ & $10.4 \pm 1.6$ & $11.0 \pm 1.3$ & $11.5 \pm 1.3$ & $11.6 \pm 1.6$ \\
\hline Haematocrit & & & & & & \\
\hline Male [17] & $0.38 \pm .05$ & $0.37 \pm .03$ & $0.36 \pm .0 .6$ & $0.36 \pm .03$ & $0.37 \pm .03$ & $0.38 \pm .04$ \\
\hline Female [14] & $0.36 \pm .04$ & $0.34 \pm .05$ & $0.36 \pm .06$ & $0.36 \pm .03$ & $0.37 \pm .03$ & $0.38 \pm .04$ \\
\hline ESR (mm/h) & & & & & & \\
\hline Male [16] & $44.8 \pm 30.7$ & $56.4 \pm 34.1$ & $55.8 \pm 24.5$ & $55.6 \pm 33.5$ & $51.3 \pm 27.3$ & $52.9 \pm 38.2$ \\
\hline Female [13] & $67.2 \pm 35.0$ & $54.3 \pm 38.1$ & $92.6 \pm 46.0$ & $78.2 \pm 23.8$ & $64.3 \pm 30.1$ & $56.7 \pm 25.9$ \\
\hline Total WBC (x10/L) [31] & $7.9 \pm 3.7$ & $5.4 \pm 1.5$ & $5.8 \pm 1.5$ & $6.1 \pm 1.7$ & $5.9 \pm 2.0$ & $6.3 \pm 1.6$ \\
\hline Platelet(x 10 $\mathbf{1 0} / \mathbf{L 0}[\mathbf{3 1}]$ & $18.7 \pm 9.9$ & $20.3 \pm 18.4$ & $27.1 \pm 12.9$ & $32.2 \pm 10.8$ & $29.3 \pm 11.9$ & $26.4 \pm 9.1$ \\
\hline Reticulocyte (\%) [25] & $1.85 \pm .60$ & $1.78 \pm .48$ & $1.89 \pm 56$ & $1.80 \pm .49$ & $1.70 \pm .36$ & $1.84 \pm .35$ \\
\hline
\end{tabular}

Table 4 Biochemical parameters for patients for the experimental period. Figures in square parentheses represent number of patients. Values are means \pm S.D.

\begin{tabular}{|c|c|c|c|c|c|c|}
\hline \multirow{2}{*}{\begin{tabular}{|l|} 
Biochemical \\
Parameter
\end{tabular}} & \multicolumn{6}{|c|}{ Day of Experimental Period } \\
\hline & $\mathbf{0}$ & 3 & 7 & 14 & 21 & 28 \\
\hline \multicolumn{7}{|c|}{ Creatinine (umol/L } \\
\hline [30] & $88.9 \pm 14.9$ & $85.4 \pm 11.6$ & $96.6 \pm 50.3$ & $72.8 \pm 16.2$ & $75.0 \pm 13.8$ & $82.5 \pm 19.6$ \\
\hline \multicolumn{7}{|l|}{ Urea (umol/L) } \\
\hline$[30]$ & $4.94 \pm 1.65$ & $4.91 \pm 2.62$ & $3.87 \pm 1.51$ & $3.52 \pm 1.22$ & $3.85 \pm 1.42$ & $4.69 \pm 2.03$ \\
\hline \multicolumn{7}{|c|}{ Aminotransferases (u/L) } \\
\hline ASAT [30] & $21.3 \pm 9.4$ & $30.1 \pm 23.9$ & $27.8 \pm 13.1$ & $27.2 \pm 17.3$ & $25.3 \pm 15.4$ & $28.8 \pm 14.6$ \\
\hline ALAT [30] & $7.2 \pm 6.3$ & $7.9 \pm 7.7$ & $10.3 \pm 8.7$ & $7.3 \pm 7.3$ & $6.7 \pm 4.4$ & $6.5 \pm 2.3$ \\
\hline \multicolumn{7}{|c|}{ Alkaline Phosphatase (u/L) } \\
\hline [30] & $84.5 \pm 56.2$ & $95.7 \pm 63.3$ & $90.0 \pm 47.1$ & $132.2 \pm 61.4$ & $102.8 \pm 84.6$ & $125.8 \pm 76.1$ \\
\hline \multicolumn{7}{|c|}{ Bilirubin (umol/L } \\
\hline Total [30] & $12.4 \pm 6.5$ & $16.4 \pm 9.1$ & $17.9 \pm 2.9$ & $15.0 \pm 7.1$ & $17.7 \pm 8.0$ & $15.1 \pm 6.2$ \\
\hline Direct [30] & $5.1 \pm 2.9$ & $7.2 \pm 2.9$ & $7.5 \pm 2.2$ & $6.5 \pm 2.7$ & $5.4 \pm 3.2$ & $7.7 \pm 2.8$ \\
\hline \multicolumn{7}{|c|}{ Total proteins $(\mathrm{g} / \mathrm{L})$} \\
\hline [30] & $77.2 \pm 4.3$ & $69.5 \pm 5.4$ & $70.0 \pm 9.0$ & $75.0 \pm 6.7$ & $76.9 \pm 6.7$ & $81.6 \pm 4.1$ \\
\hline \multicolumn{7}{|c|}{ Total Cholesterol, random (umol/L) } \\
\hline [30] & $4.02 \pm .98$ & $3.60 \pm .63$ & $3.33 \pm 1.06$ & $4.51 \pm .92$ & $4.18 \pm .91$ & $2.92 \pm .86$ \\
\hline \multicolumn{7}{|c|}{ Glucose (umol/L) } \\
\hline [30] & $6.03 \pm 1.07$ & $5.68 \pm .98$ & $5.32 \pm .96$ & $5.39 \pm .81$ & $5.29 \pm .81$ & $5.58 \pm 2.80$ \\
\hline \multicolumn{7}{|c|}{ Uric Acid (umol/L x 100) } \\
\hline Male [16] & $2.19 \pm .69$ & $4.31 \pm 1.05$ & $4.17 \pm 1.54$ & $2.64 \pm 1.08$ & $2.55 \pm .82$ & $3.73 \pm .84$ \\
\hline Female [14] & $2.12 \pm .69$ & $3.69 \pm 1.09$ & $3.04 \pm 1.05$ & $2.90 \pm 1.01$ & $1.90 \pm .27$ & $2.95 \pm .41$ \\
\hline
\end{tabular}




\section{Laboratory data}

The haematological data is presented in Table 3. The mean haemoglobin levels were lower during treatment, compared to pretreatment values, but started to rise by Day 14, approaching pre-treatment levels by Day 28 . Total WBC count dropped from the pre-treatment level and remained low throughout the 28-day study period although the post-treatment values were higher than the values during treatment. Platelet count increased progressively with treatment, from a low pre-treatment value to upper normal values and began to decline after Day 14. ESR, haematocrit and reticulocyte counts showed little change from the pre-treatment values with treatment.

The majority of biochemical parameters in the patients were not significantly modified following treatment (Table 4). All mean values determined for creatinine and urea, which reflect renal function, were within the range considered as normal. Of the indices of liver function, both total and direct bilirubin appeared elevated compared to pre-treatment values but the levels were all within the range considered normal. Alkaline phosphatase (ALP) levels were persistently elevated throughout the study period compared to the pre-treatment values, with peak levels on Day 14 . There were no significant differences in the two aminotransferases measured (ASAT and ALAT), although the values were generally higher during and after treatment. Level of total protein and glucose did not change significantly with treatment. Total cholesterol level dropped during treatment rose on Day 14 and was again significantly lower than pre-treatment values by Day 28 .

Serum uric acid levels showed a significant rise during treatment (Day 3) and remained higher than pretreatment values until the last week of the study period. Statistical comparison of the various parameters yielded p-value $>0.05$ in all cases. This implies that there was no statistical significant difference between the effect of the drug and the normal state.

\section{DISCUSSION}

This open study was designed to investigate the clinical efficacy of the tea-bag formulation of $C$. sanguinolenta root powder for the treatment of acute uncomplicated falciparum malaria in a Ghanaian population. The overall cure rate was $93.5 \%$. There were two cases of late recrudescence on Days 21 and 28. These could be due to re-infection as this was an out-patient study.

In this study the mean parasite clearance time was $82.3 \mathrm{~h}$ and the fever clearance time was $24.5 \mathrm{~h}$. These values are comparable to the ones obtained in the preliminary clinical study when $C$. sanguinolenta aqueous extract was used. In the study comparing the efficacy of aqueous extract of $C$. sanguinolenta to that of chloroquine, the parasite and fever clearance times for the patients on chloroquine were $56 \mathrm{~h}$ and $48 \mathrm{~h}$ respectively. $C$. sanguinolenta was better at fever clearance than chloroquine. In addition, unlike patients in the chloroquine treated group, patients in the cryptolepis treated group did not require antipyretics. The short fever clearance time for PHYTO-LARIA ${ }^{\circledR}$ in this study is likely due to the antipyretic property reported for C. sanguinolenta. ${ }^{27,28}$

From the results of the evolution of presenting symptoms shown in Table 2, one could regard the symptoms with a very high incidence $(>90 \%)$ as the ones which are characteristic of falciparum malaria. These were body ache, chills, fever, headache and weakness. Of these, chills and fever cleared rapidly in all patients and were completely resolved by Day 7 when the parasitaemia cleared. The other symptoms are those related to pain and they persisted in some patients throughout the experimental period. Approximately $25 \%$ of the patients still had headaches on Day 7 when they had no parasites in the blood.

A number of abnormalities in laboratory values in haematology and biochemistry were present before treatment. The resolution of these abnormalities posttreatment was slow generally. This is a feature commonly seen in malaria post-treatment. For example, the haemoglobin pattern showed the usual low levels of the protein, contributing to weakness, one The most persistent symptoms post-treatment. Thrombocytopenia is frequently associated with acute malaria. Therefore, the progressive increase in platelet count after treatment could be regarded as indicative of the effectiveness of the test drug against falciparum malaria. The persistence of alkaline phosphatase elevation has been noted with halofantrine ${ }^{29}$. The laboratory findings do not suggest toxicity of the test drug, although a recent publication suggests that the herb can be genotoxic to mammalian cells ${ }^{30}$. It has also been found to induce dose-dependent anxiety in mice. ${ }^{31}$

There is evidence of chloroquine resistance in Ghana ${ }^{32}$ hence drugs such as artesunate-amodiaquine combination have replaced chloroquine for malaria treatment. $C$. sanguinolenta and the indoquinoline alkaloids isolated from it have been shown to be effective against chloroquine-resistant strains of the parasite..$^{9,10,12}$

Therefore, although chloroquine resistance was not part of the study, the high cure rate reported would tend to suggest that the tea bag formulation of the root powder of $C$. sanguinolenta could be used for the treatment of 
malaria caused by chloroquine-resistant strain of $P$. falciparum.

Evaluated on evidence of fever clearance and disappearance of parasitaemia by Day 7, according to the modified WHO criteria, the tea bag formulation of the root powder of $C$. sanguinolenta has been shown to be highly effective in the treatment of acute uncomplicated malaria.

\section{ACKNOWLEDGEMENT}

The authors wish to express their sincere appreciation to Professor David Ofori-Adjei, Noguchi Memorial Institute for Medical Research, University of Ghana, Accra, Ghana for his guidance and support in the analysis and preparation of the manuscript. We also acknowledge the immense help of Mrs Doris Klufio of Korle-Bu Teaching Hospital as nurse for the project.

\section{MEMORIAM}

This article is dedicated to the memory of Professor G.L. Boye who passed away before the article was accepted for publication.

\section{REFERENCES}

1. Tackie AN, Boye GL, Sharaf MHM, Schiff Jr. PL, Crouch RC, Spizer RL, Johnson JD, Minick D, Dunn J, Martin GE. Cryptospirolepine, a unique spiro-nonacyclic alkaloid isolated from Cryptolepis sanguinolenta. J Nat Prod 1993; 56: 653-670

2. Irvine FR. Woody Plants of Ghana.1961; Oxford University Press. London

3. Boakye-Yiadom K. Antimicrobial properties of some West African medicinal plants II. Antimicrobial activity of aqueous extracts of Cryptolepis sanguinolenta (Lindl.) Schlechter. Quart J Crude Drug Res. 1979; 17:78-80

4. Boye GL, Ampofo O. Clinical uses of Cryptolepis sanguinolenta (Asclepidaceae). Proceedings of the First International Seminar on Cryptolepine. University of Science and Technology. 1983. Kumasi, Ghana. p 37.

5. Oliver-Bever BEP. Medicinal Plants in Tropical West Africa 1986. Cambridge University Press, Cambridge p 18, 41, 131, 205

6. Paulo A, Duarte A, Gomes ET. In vitro antibacterial screening of Cryptolepis sanguinolenta alkaloids. J Ethnopharmacol 1994; 44:127-130

7. Sofowora A. Medicinal Plants and Traditional Medicine in Africa 1982. John Wiley and Sons. Chichester p221-223

8. Silva O, Duarte A., Cabrita J, Pimentel M, Diniz A, Gomes E. Antimicrobial activity of Guinea-
Bissau traditional remedies. J Ethnopharmacol 1996; 50: 55-59

9. Wright CW, Phillipson JD, Awe SO, Kirby GC, Warhurst DC, Quertin-Leclerq J, Angenot L. Antimalarial activity of cryptolepine and some other anhydronium bases. Phytother Res 1996; 10:361-363

10. Cimanga K, De Bruyne T, Pieters L, Vlietinck AJ, Turger C.A. In vitro and in vivo antiplasmodial activity of cryptolepine and related alkaloids from Cryptolepis sanguinolenta. J Nat Prod 1997; 60:688-691

11. Grellier P, Ramiaramanana L, Milleriox V, Deharo E, Shrevel J, Frappier F. Antimalarial activity of cryptolepine and isocryptolepine, alkaloids isolated from Cryptolepis sanguinolenta. Phytother Res 1996; 10: 317-321

12. Kirby GC, Paine A, Warhurst DC, Noamesi BK, Phillipson JD. In vitro and in vivo antimalarial activity of cryptolepine, a plant-derived indoloquinoline. Phytother Res 1995; 9: 359-363

13. Noamesi BK, Paine A, Kirby GC, Warhurst DC, Phillipson JD. In vitro antimalarial activity of cryptolepine, an indoquinoline. Trans Roy Soc Trop Med Hyg 1991; 85:315

14. Boakye-Yiadom K, Herman Ackah SM. Cryptolepine hydrochloride: Effect on Staphylococcus aureus. J Pharm Sci 1979; 68:1510-154

15. Cimanga K, De Bruyne T, Lasure A, Van Poel B, Pieters L, Claeys M, Vanden Berghe D, Kambu K, Tona L, Vlietinck AJ (1996 ) In vitro biological activities of alkaloids from Cryptolepis sanguinolenta. Planta Med 1996a; 62: 22-27

16. Cimanga K, Pieters L, Claeys M, Vanden Berghe D, Vlietinck AJ. Biological activities of cryptolepine, an alkaloid from Cryptolepis sanguinolenta. Planta Med 1991; 57 Suppl 2: A98A99

17. Cimanga K, De Bruyne T, Pieters L, Totte J, Tona L, Kambu K, Vanden Berghe D, Vlietinck AJ. Antibacterial and antifungal activities of neocryptolepine, biscryptolepine and cryptoquindoline, alkaloids isolated from Cryptolepis sanguinolenta. Phytomed 1998; 5: 209-214

18. Paulo A, Pimentel M, Viegas S, Pires I, Duarte A, Cabrita J, Gomes. Cryptolepis sanguinolenta activity against diarrhoeal bacteria. $J$ Ethnopharmacol 1994; 44: 73-77

19. Sawer IK. Berry MI, Brown MW, Ford JL. Antimicrobial activity of cryptolepine. J Pharm Pharmacol 1993; 45:1108-1111

20. Sawer IM, Brown MW, Ford JL. The effect of cryptolepine on the morphology and survival; of Escherichia coli, Candida albicans and 
Saccharomyces cerevisiae. J Appl Bact 1995; 79:314-321

21. Tona L, Kambu K, Ngimbi N, Cimanga K, Vlietinck AJ. Antiamoebic and phytochemical screening of some Congolese medicinal plants. $J$ Ethnopharmacol 1998; 61: 57-65

22. Bierer DE, Fort DM, Mendez CD, Luo J, Imbach PA, Dubenko LG, Jolad SD, Gerber RE, Litvac J, Lu Q, Zhang P, Reed MJ, Waldeck N, Bruening RC, Noamesi BK, Hector RF, Carlson TJ, King SR. Ethnobotanical-directed discovery of the antihyperglycaemic properties of cryptolepine: its isolation from Cryptolepis sanguinolenta, synthesis, and in vitro and in vivo activities. $\mathrm{J} \mathrm{Med}$ Chem 1998; 41:894-901

23. Luo J, Fort DM, Carlson TJ, Noamesi BK, Nii Amon-Kotey D, King SR, Tsai J, Quan J, Hobensack C, Lapresca P, Waldeck M, Mendez CD, Jolad SD, Bierer DE, Reaven GM. Cryptolepis sanguinolenta: an ethnobotanical approach to drug discovery and the isolation of a potentially useful new antihyperglycaemic agent. Diabet Med 1998; 15:367-374

24. Bamgbose SOA, Noamesi, BK. Studies on cryptolepine II: Inhibition of carrageenan-induced oedema by cryptolepine. Planta Med 1981; 41:392-396

25. Boye GL. Studies on antimalarial action of Cryptolepis sanguinolenta extract. Proceedings of the International Symposium on East-West Medicine. 1989. October 10-11; p 243 - 251. Seoul, Korea.

26. WHO. Advances in Malaria Chemotherapy. Report of WHO Scientific Group. 1984. Technical Report Series 711

27. Raymond-Hamet. Sur quelque propriétés physiologiques des alcaloides du Cryptolepis sanguinolenta Schlechter. Comptes Rendus Société Biologie 1937; 126: 768-770

28. Noamesi BK. Some pharmacological actions of alkaloid cryptolepine from Cryptolepis sanguinolenta. Ph. D. Thesis. 1983. University of Lagos, Nigeria

29. Ofori-Adjei D, Parr SNL. Halofantrine for falciparum malaria in Ghana. J Pharm Med 1992; 2:229-240

30. Ansah C, Khan A, Gooderham NJ. In vitro genotoxicity of West African anti-malarial herbal Cryptolepis sanguinolenta and its major alkaloid cryptolepine. Toxicology 2005; 208:141-147

31. Ansah C, Mfoafo EAA, Woode E, Duwiejua M. Anxiogenic Effects of an Aqueous Crude Extract of Cryptolepis sanguinolenta (Periplocaeaeceae) in Mice. Int J Pharmacol 2008; 4: 20-26

32. Ofori-Adjei D, Adjepon-Yamoah KK. Commey JOO, Ofori-Adjei E. In vivo sensitivity of $P$. falciparum to chloroquine in Accra. Ghana Med $J$ 1988; 22:11-14 